\title{
The Impact of Beta Brain Waves in Improving Cognitive Function through Brain Jogging Applications
}

\author{
Yudy Hendrayana*, Jajat Darajat Kusumah Negara, Nuryadi, Agus Gumilar, Martina Lesyiana \\ Department of Sport Education, Faculty of Sport Education and Health, Universitas Pendidikan Indonesia, Bandung, 40154, Indonesia
}

Received September 22, 2020; Revised November 27, 2020; Accepted December 22, 2020

\section{Cite This Paper in the following Citation Styles}

(a): [1] Yudy Hendrayana, Jajat Darajat Kusumah Negara, Nuryadi, Agus Gumilar, Martina Lesyiana, "The Impact of Beta Brain Waves in Improving Cognitive Function through Brain Jogging Applications," International Journal of Human Movement and Sports Sciences, Vol. 8, No. 6A, pp. 73-77, 2020. DOI: 10.13189/saj.2020.080713.

(b): Yudy Hendrayana, Jajat Darajat Kusumah Negara, Nuryadi, Agus Gumilar, Martina Lesyiana (2020). The Impact of Beta Brain Waves in Improving Cognitive Function through Brain Jogging Applications. International Journal of Human Movement and Sports Sciences, 8(6A), 73-77. DOI: 10.13189/saj.2020.080713.

Copyright $\odot 2020$ by authors, all rights reserved. Authors agree that this article remains permanently open access under the terms of the Creative Commons Attribution License 4.0 International License

\begin{abstract}
Cognitive function is a process of thinking systematically, logically, and analytically. In the present study, it is indispensible and has an important role in the learning process's success. The enhancement of cognition could change a person's behavior for the better. The thought process depends on the brain's electrical activity and a person's mental condition, which is indicated by brain waves, beta waves. Beta waves affect a person's concentration and awareness. Improvement beta waves on adolescents are positively correlated with improved cognitive function. In addition to cognitive function, they are stimulation by brain jogging or brain exercise. Brain jogging is a mental exercise model that combines cognitive and multitasking. This study used an experimental method with brain jogging treatment intervention for eight weeks, with 17 students who had met the sampling criteria. The beta wave measurement results increased significantly by $19.92 \%$ or $(16.99 \pm 8.48$ vs. $20.38 \pm 9.34)$ with a p-value of $0.0001^{* *}$. Cognitive function increased significantly by $44.36 \%$ or $(290.88 \pm 31.92$ vs. $419.94 \pm 97.01)$ with a p-value of $0.0001^{* *}$. Meanwhile, the Pearson correlation test results between beta waves and cognitive function in the pre-test obtained $\mathrm{r}=-0.642$ with a determinant coefficient of 0.054 or $5.4 \%$, there was no significant correlation, while in the post-test it was obtained $r=0.482$ with a determinant coefficient of 0.232 . or $23.2 \%$ with a p-value of $0.050^{*}$. Research and analysis of brain jogging treatment have been shown to improve cognitive function and affect beta waves.
\end{abstract}

Keywords Beta waves, Cognitive Function, Brain Jogging

\section{Introduction}

Cognitive factors have an essential role in the success of students in the learning process. The ability of cognitive function will have a positive impact on students' learning outcomes. Therefore, we need a method or formula to improve students' cognitive function and look for any factors that can affect cognitive function development. Cognitive concepts refer to the ability to process information, apply knowledge, and change trends [1]. In line with the theory of Jean Piaget in [2] found that cognitive development is the combined result of maturity, maturity of the brain and nervous system, and adaptation to our environment.

Cognitive activity is an individual behavior that has an impact on gaining knowledge. In addition, cognitive is also a mental condition because of indirect observations of cognition. Hence, cognition cannot be measured directly but through observable behavior. According to Mayers, Cognition refers to all mental activities associated with thinking, knowing, remembering, involves many modes of understanding, such as perception, imagination, reasoning, observation, response, memory.[3] Cognition also involves forms of recognition, such as observing, seeing, watching, imagining, giving, guessing, and 
judging. Cognitive is always the main thing to determine someone in responding, thinking, processing information, storing information to get a pattern from a new environment [4].

Cognitive function is a conscious mental activity such as thinking, remembering, learning and using language. Similar research with that cognitive function consists of 5 domains: Attention and Concentration, Memory, Visuospatial, Language, and Executive Functions. Concentration is one of 5 cognitive processes. Cognitive enhancement may be defined as the amplification or extension of the mind's core capacities by improving or augmentation of internal or external information processing systems [5]. The benefit if someone can concentrate well when participating in the learning process in class, including students, will more easily and quickly master the teaching material presented, likewise with four other cognitive function domains, namely memory, visuospatial, language and executive functions which can affect student learning and learning outcomes. To detect someone is focused or not and could be analyzing through brain waves [5].

Sports science researchers have been interested in the relationship between brainwaves and sports performance. In the normal activities of EEG, $\theta$ and $\delta$ activities are rare or non-existent. The activated cortex can produce $\gamma$ activity and $\beta$, and sometimes $\alpha$ activity [6]. Most researchers working on brainwaves in the past focused only on closed-skill precision sports and found that the $\alpha$-wave in the temporal lobe region is the basis of closed-skill sports [7]. Brain waves are divided into five distinct parts, which create a spectrum of levels of human consciousness. Brain waves can change throughout the day, which is influenced by the activities carried out. The activities carried out can be influenced by several factors: a person's emotional condition, adequate sleep time, and a person's stress condition. The brain is made up of billions of brain cells called neurons. Each neuron communicates with each other (establishes a relationship) by emitting electric waves. The electrical waves released by neurons in the brain are called brain waves. So what is called brain waves are electrical activities released by the brain? [8]. Similar research with the description above states that brain waves can be categorized into 5 (five) categories, namely delta, theta, alpha, beta, and gamma. Brain waves related to cognitive function are beta brain waves. The state of alert and full concentration is strongly influenced by beta brain waves (13-30 Hz) in beta brain waves, our mind remains sharp and focused on activities[9].

From the problems described above, it can be seen that cognitive function plays an essential role in the learning process. One way to influence cognitive function is the application of brain jogging, including light exercise and brain exercise.[10] Brain jogging is a mental exercise model that combines cognitive and multitasking. One of the mental training programs that can be given to students at school is brain jogging training.[11] This training model provides new inspiration for every individual in mental training, especially in improving cognitive function. In its implementation, brain jogging combines three critical elements: cognitive, multitasking, and physical activity[12]. After reviewing several studies, results show that brain jogging affects increasing concentration, as proven by that the brain gym method affects improving students' concentration skills.[13] The other research found that brain jogging is one of the training methods to improve one's cognitive and mental aspects. This study proves that brain jogging training can significantly influence self-confidence and skills learning outcomes.[14]-[16].

\section{Material and Method}

The research design used pretest - posttest control design and experimental research that was carried out in one group randomly selected. This study population was 30 students who are members of the Softball Student Activity Unit at the Indonesia University of Education. The sample was selected based on simple random sampling amount 17 subjects that met the inclusion criteria, namely the Body Mass Index in the healthy category, had no history of chronic disease, as a beginner softball player or with less than one year of training experience, and gender Male. The research instruments used in this study included cognitive function (attention, memory, language, visual, executive function), measurement of attention with a grid exercise concentration test; memory measurement with digit span test; language, visuospatial, and executive function with tests of academic potency. Neurosky Mindwave Mobile's beta brain wave measurement is an electroencephalograph (EEG) research instrument that detects gamma brain waves in the frequency range $12-38 \mathrm{~Hz}$ range. WujiBrain software for mac v. 127

Research protocol, all research subjects get information and socialization about the aims and objectives of the research. Furthermore, it continued by filling in the Inform Consent. Then the initial beta brain wave data were collected while performing cognitive function tests. The research intervention was carried out eight weeks three times per week, namely the application of the brain jogging program. After completing the treatment, the final data measurement was carried out again with the same test instrument as the initial test. Data were collected and analyzed using the comparative independent $t$-test analysis to compare the gain score between experiment groups with control groups data. The end of the study was analyzed and concluded according to the research objectives. 


\section{Result}

Table 1. Demography of research subject

\begin{tabular}{|c|c|c|c|c|}
\hline Parameters & Mean \pm SD & Min & Max & N \\
\cline { 1 - 4 } Height $(\mathrm{m})$ & $1,68 \pm 0,05$ & 1,60 & 1,77 & \multirow{2}{*}{17} \\
\cline { 1 - 3 } Weight $(\mathrm{Kg})$ & $64,06 \pm 9,63$ & 49 & 82 & \\
\cline { 1 - 4 } BMI & $22,54 \pm 3,04$ & 18,90 & 30,86 & \\
\hline
\end{tabular}

BMI: Body Mass Index

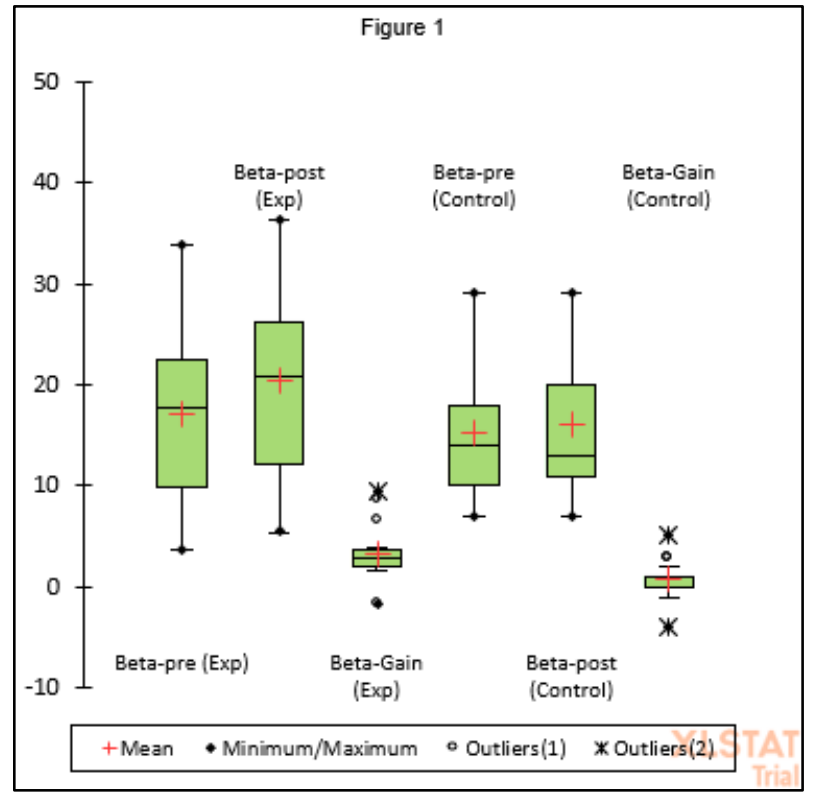

Figure 1. Beta waves data are shows of pre-post on experiment groups, $(16,99 \pm 8,23$ vs. $20,38 \pm 9,06)$. Pre-post on control groups, $(15,24 \pm 6,66$ vs. $16,01 \pm 6,92)$. Gain score the beta waves between experiment and control groups: $(3,38 \pm 2,65$ vs. $0,82 \pm 1,94)$.

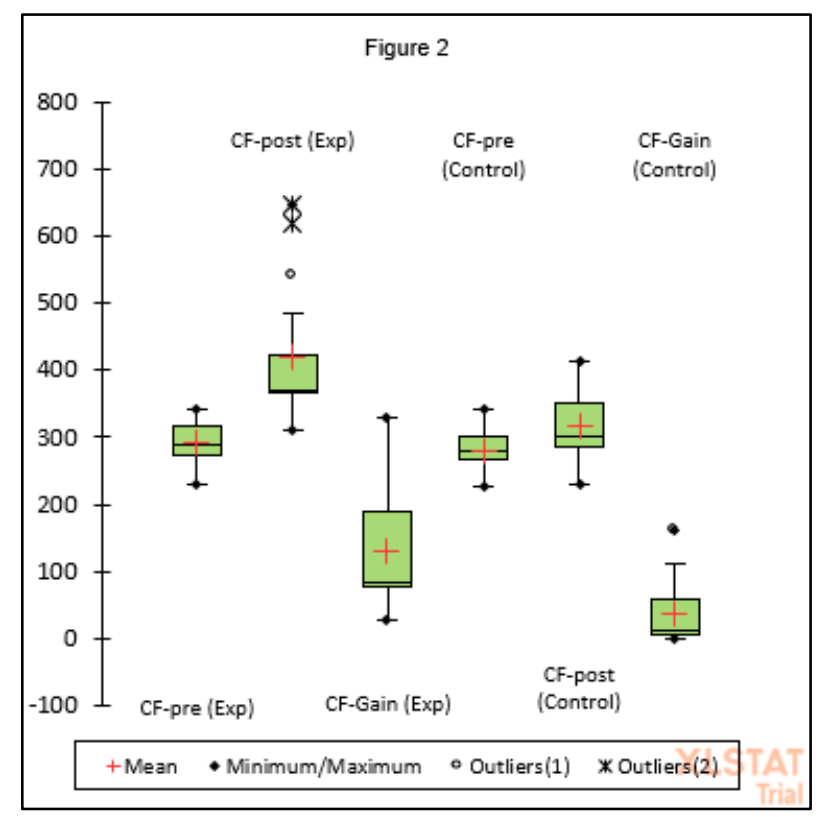

Figure 2. Cognitive function data are shows of pre-post on experiment groups, (290,88 $\pm 30,97$ vs. 419,94 $\pm 94,12)$. Pre-post on control groups, $(110,45 \pm 130,24$ vs $318,24 \pm 50,29)$. Gain score the cognitive function between experiment and control groups: $(129,06 \pm 95,87$ vs $37,49 \pm$ $45,63)$.

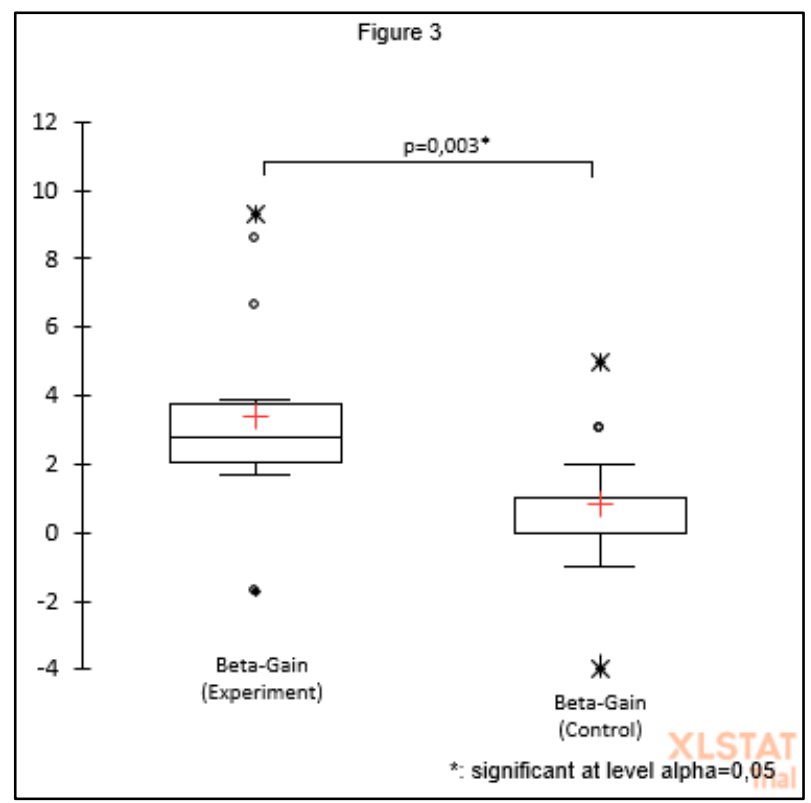

Figure 3. The result of independent t-test statistical analysis on beta wave experiment groups $(19,92 \%)$ compare to control groups $(5,41 \%)$. There is significant difference at $p$-value $0,003 *$.

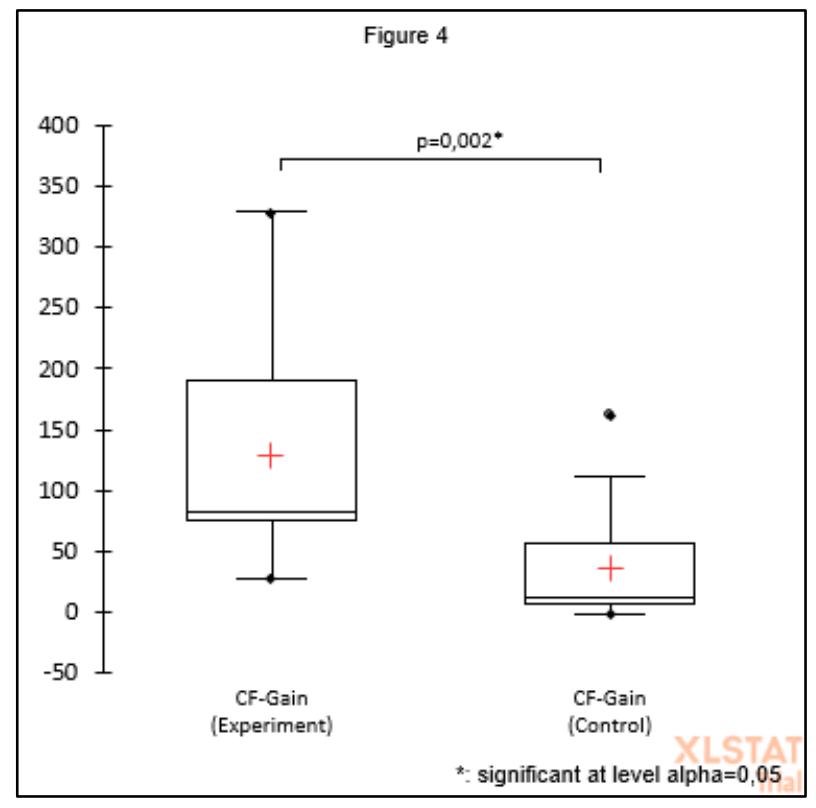

Figure 4. Base on independent t-test on cognitive function variable, experiment groups $(44,37 \%)$ compare to control groups $(13,35 \%)$. There is significant difference at p-value $0,002 *$.

\section{Conclusions}

The results of the paired t-test analysis on beta wave variables and cognitive function showed a significant difference. That means that the application of the brain jogging treatment could affect beta waves and cognitive function following the aim of this study to determine the effect of brain jogging [17], which interacts with beta waves and cognitive function. The other side is with 
research conducted by Jang et al. found that the increase in beta waves is a neurofeedback and can affect cognitive function improvement [17], [18]. The results of other studies suggest that brain jogging can improve cognitive and mental function.[13]. Beta wave and cognitive function have a similar increase on students who treated brain jogging application. Similar to this finding, significant enhancements of $\beta$-wave were found in some studies using bicycle dynamometer to perform high-intensity exercise and incremental intensity exercise [19], [20]. Youngstedt et al., observed that after acute exercises, although there were no correlated changes of body temperature and anxiety state, the brainwave activities of $\beta$-wave showed an upward trend. This study we found no significant differences in $\beta$-wave during running before the heart rate reaching [20]. However, when the heart rate of the participants exceeded $75-85 \%$ of the maximum heart rate in the process of high-intensity exercises, a decreased $\beta$-wave activity was reported when oxygen was lacking in the brain and blood flow [21]. Fumoto et al., observed participants performing bicycle ergometer exercise for $15 \mathrm{~min}$ and found that $\alpha$-wave was significantly increased in the accelerating process of exercise. In our study, $\alpha$-wave showed an upward trend but no significant differences in the running It is contradictory at the beginning of the study, namely that an increase does not match the increase in beta waves in cognitive function. Several studies have found that beta waves can improve cognitive function.[5], [17], [27], [28] exercise even though the heart rate reached $150 \mathrm{~min}-1$ [22].

More significant amounts of physical activity and higher cardiorespiratory fitness levels are associated with better cognitive function in older adults [23]. For example, older adult athletes outperform their more sedentary peers on many different cognitive tasks, and fitter individuals are faster and more accurate on executive functioning and memory tasks [24]. Longitudinal studies of physical activity have also found that engaging in a greater amount of physical activity earlier in life is associated with better cognitive function later in life, [25] with larger effects for individuals engaging in more intense exercises. However, cross-sectional and longitudinal observational studies are often plagued by confounding factors that make it challenging to make causal claims about the link between physical activity and cognitive function.[26] Evaluation in each process and learning tools can solve learning problems[29].

\section{Acknowledgments}

This research will be dedicated to the progress and development of softball and baseball athletes in West Java province and the Indonesian elite athletes.

\section{REFERENCES}

[1] E. Neher, "What is Rate-Limiting during Sustained Synaptic Activity: Vesicle Supply or the Availability of Release Sites.," Front. Synaptic Neurosci., vol. 2, no. September, pp. $1-6,2010$.

[2] M. R. Rueda, M. I. Posner, and K. Mary, "Developmental Neuropsychology The Development of Executive Attention : Contributions to the Emergence of Self-Regulation," Dev. Neuropsychol., vol. 28, no. August, pp. 573-594, 2005.

[3] M. Mayer, N. Kaiser, R. J. Milholland, and F. Rosen, "Cortisol binding in rat skeletal muscle," J. Biol. Chem., vol. 250, no. 4, pp. 1207-1211, 1975.

[4] A. Azhari and F. I. Ammatulloh, "Classification of Concentration Levels in Adult-Early Phase using Brainwave Signals by Applying K-Nearest Neighbor," Signal Image Process. Lett., vol. 1, no. 1, pp. 14-24, 2019.

[5] N. Bostrom and A. Sandberg, "Cognitive enhancement: Methods, ethics, regulatory challenges," Sci. Eng. Ethics, vol. 15, no. 3, pp. 311-341, 2009.

[6] R. Miller, "Theory of the normal waking EEG: From single neurones to waveforms in the alpha, beta and gamma frequency ranges," Int. J. Psychophysiol., vol. 64, no. 1, pp. 18-23, 2007.

[7] A. J. Haufler, T. W. Spalding, D. L. Santa Maria, and B. D. Hatfield, "Neuro-cognitive activity during a self-paced visuospatial task: Comparative EEG profiles in marksmen and novice shooters," Biol. Psychol., vol. 53, no. 2-3, pp. 131-160, 2000.

[8] D. Chu et al., "The correlation of brainwaves of Taekwondo athletes with training vis-à-vis competition performance-an explorative study," Int. J. Perform. Anal. Sport, vol. 18, no. 1, pp. 69-77, 2018.

[9] Z. H. Murat, M. N. Taib, Z. M. Hanafiah, S. Lias, R. S. S. A. Kadir, and H. A. Rahman, "Initial investigation of brainwave synchronization after five sessions of horizontal rotation intervention using EEG," Proc. 2009 5th Int. Colloq. Signal Process. Its Appl. CSPA 2009, pp. 350-354, 2009.

[10] B. J. Sadock and V. A. Sadock, Comprehensive Textbook \& Psichiatry, vol. 15, no. 7. Lippincott Williams \& Wilkins Publishers, 200AD.

[11] T. . Weng et al., "The Acute Effects of Aerobic Exercise on the Functional Connectivity of Human Brain Networks," Brain Plast., vol. 2, no. 2, pp. 171-190, 2017.

[12] A. P. Jr and F. A. Furlan, "ARBS Annual Review of Biomedical Sciences Biomolecular Information, Brain Activity and Cognitive Functions," ARBS Annu. Rev. Biomed. Sci., pp. 12-29, 2007.

[13] P. Engchuan, K. Wongsuphasawat, and P. Sittiprapaporn, "Brain electrical activity during bench press weight training exercise," Asian J. Med. Sci., vol. 10, no. 5, pp. 80-85, 2019.

[14] J. Zhao and G. Li, "Application of Brain Science in Physical Education and Teaching," Educ. Sci. Theory Pract., vol. 18, no. 5, pp. 2155-2161, 2018.

[15] J. K. N. Darajat, Nuryadi, and A. Gumilar, "The Effect of Physical Fitness and Healthy Behavior toward 
Concentration, Anxiety and Cortisol Hormone," in IOP Conference Series: Materials Science and Engineering, 2017, vol. 180 , no. 1 .

[16] N. Nuryadi, J. Darajat Kusumanegara, L. Angkawidjaja, A. Gumilar, and C. Ubad Abdullah, "Response Of Cortisol Hormone To Students' Anxiety And Focus," J. Eng. Sci. Technol., vol. 14, no. 6, pp. 3185-3193, 2019.

[17] J. H. Jang et al., "Beta wave enhancement neurofeedback improves cognitive functions in patients with mild cognitive impairment: A preliminary pilot study," Med. (United States), vol. 98, no. 50, 2019.

[18] K. H. Ashe, "Learning and memory in transgenic mice modeling Alzheimer's disease," Learning and Memory, vol. 8, no. 6. pp. 301-308, 2001.

[19] S. Schneider, V. Brümmer, T. Abel, C. D. Askew, and H. K. Strüder, "Changes in brain cortical activity measured by EEG are related to individual exercise preferences," Physiol. Behav., vol. 98, no. 4, pp. 447-452, 2009.

[20] S. D. Youngstedt, R. K. Dishman, K. J. Cureton, and L. J. Peacock, "Does body temperature mediate anxiolytic effects of acute exercise?," J. Appl. Physiol., vol. 74, no. 2, pp. 825$831,1993$.

[21] V. Kraaier, A. C. Van Huffelen, G. H. Wieneke, H. B. Van der Worp, and P. R. Bär, "Quantitative EEG changes due to cerebral vasoconstriction. Indomethacin versus hyperventilation-induced reduction in cerebral blood flow in normal subjects," Electroencephalogr. Clin. Neurophysiol., vol. 82, no. 3, pp. 208-212, 1992.

[22] M. Fumoto et al., "Ventral prefrontal cortex and serotonergic system activation during pedaling exercise induces negative mood improvement and increased alpha band in EEG," Behav. Brain Res., vol. 213, no. 1, pp. 1-9, 2010

[23] K. I. Erickson, A. G. Gildengers, and M. A. Butters, "Treatmentresearch: Physical activity and brain plasticity in late adulthood," Dialogues Clin. Neurosci., vol. 15, no. 1, pp. 99-108, 2013.

[24] C. Cetinkaya et al., "Positive effects of aerobic exercise on learning and memory functioning, which correlate with hippocampal IGF-1 increase in adolescent rats.," Neurosci. Lett., vol. 549, pp. 177-181, Aug. 2013.

[25] W. T.B. et al., "The Acute Effects of Aerobic Exercise on the Functional Connectivity of Human Brain Networks," Brain Plast., vol. 2, no. 2, pp. 171-190, 2017.

[26] R. C. Cassilhas et al., "The impact of resistance exercise on the cognitive function of the elderly.," Med. Sci. Sports Exerc., vol. 39, no. 8, pp. 1401-1407, Aug. 2007.

[27] S. B. Cooper, S. Bandelow, and M. E. Nevill, "Breakfast consumption and cognitive function in," 2010.

[28] J. H. MacCabe et al., "Decline in cognitive performance between ages 13 and 18 years and the risk for psychosis in adulthood: A swedish longitudinal cohort study in males," JAMA Psychiatry, vol. 70, no. 3, pp. 261-270, 2013.

[29] Muslimin and Destriana, "Evaluation of curriculum implementation of 13 sports and health education teachers," Univers. J. Educ. Res., vol. 8, no. 1, pp. 27-35, 2020, doi: 10.13189/ujer.2020.0801 